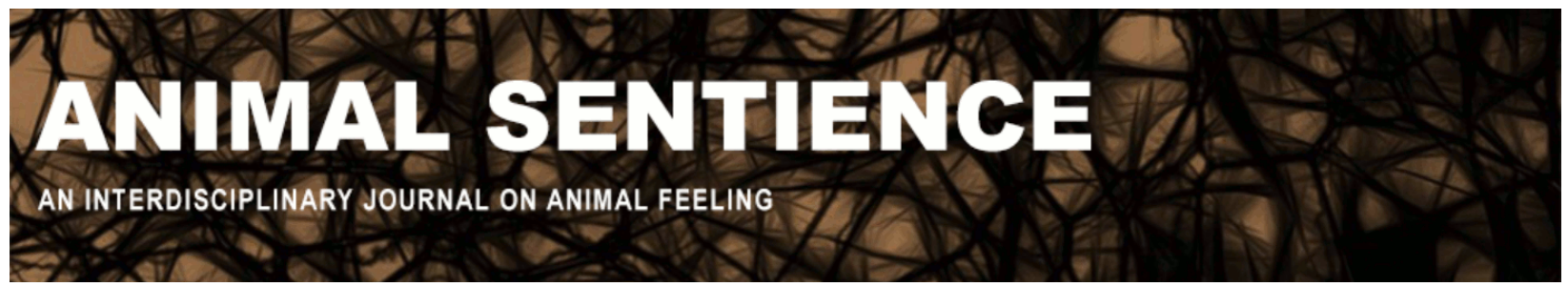

Mehrkam, Lindsay R. (2019) A behavior-analytic approach to understanding octopus "mind". Animal Sentience 26(12)

DOI: $10.51291 / 2377-7478.1491$

Date of submission: 2019-06-11

Date of acceptance: 2019-06-16 (c) 


\title{
A behavior-analytic approach to understanding octopus "mind"
}

\author{
Commentary on Mather on Octopus Mind
}

\author{
Lindsay R. Mehrkam \\ Department of Psychology \\ Monmouth University
}

\begin{abstract}
Mather makes a convincing case for octopus sentience based on a lot of evidence of their complex learning capabilities. It should follow from Mather's findings that these intelligent invertebrates are worthy of welfare considerations, just as vertebrate species with similar capabilities are. I provide a complementary environment-behavior analysis of how we might understand the world of the octopus more straightforwardly, borrowing from Mather's examples, to show how to promote opportunities for complex learning and species-typical behaviors in the octopus.
\end{abstract}

Lindsay R. Mehrkam is an assistant professor of psychology, board-certified behavior analyst, and applied animal behaviorist. Her research focuses on designing and evaluating behavioral interventions to promote both human and animal welfare in society. Website

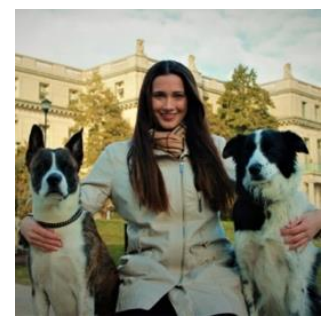

Mather's comprehensive account of the behavior and the perceptual world of the octopus leaves little doubt that they are intelligent, sentient, and capable of a range of complex learning about their environment. Many of these capabilities are also evident in other species that are already accorded higher welfare standards. Mather carefully considers a case for an octopus "mind." The existence of a mind is not necessary to establish that these animals are complex learners, worthy of welfare considerations. That we can directly observe them engaging in a wide range of intricate, voluntary behaviors - and learning about the consequences of those behaviors - is clear and convincing evidence. I offer here a more parsimonious, behavioral explanation of the range of learning capabilities exhibited by the octopus that may generalize to applied settings.

\section{Environmental Antecedents and Consequences of Octopus Behaviors}

In the study of operant behavior (voluntary behavior modified by its consequences), the fundamental unit of analysis is the three-term contingency, consisting of a behavior, its antecedents, and its consequences (Moxley, 1996). Antecedents are events that occur immediately prior to the behavior, and consequences are events that occur immediately after. A range of potential antecedent and consequent events for a selection of octopus species-typical behaviors (based on Mather) is presented below: 


\begin{tabular}{|l|l|l|}
\hline Antecedent & Behavior & Consequence \\
\hline $\begin{array}{l}\text { Change in substrate; } \\
\text { presence of threat and/or } \\
\text { availability of prey/mate }\end{array}$ & $\begin{array}{l}\text { Skin color changes } \\
\text { (camouflage) }\end{array}$ & $\begin{array}{l}\text { Increased likelihood of } \\
\text { obtaining prey/food; } \\
\text { avoiding threat or predator; } \\
\text { increased likelihood of } \\
\text { copulation with mate }\end{array}$ \\
\hline Presence of threat & Dark eye contrast & $\begin{array}{l}\text { Avoidance of/escape from } \\
\text { threat or predator }\end{array}$ \\
\hline $\begin{array}{l}\text { Presence or availability of } \\
\text { prey }\end{array}$ & "Passing Cloud" & $\begin{array}{l}\text { Increased rate of movement; } \\
\text { closer proximity to prey; } \\
\text { increased distance to threat }\end{array}$ \\
\hline Availability of prey & $\begin{array}{l}\text { Obtaining and consuming } \\
\text { prey }\end{array}$ \\
\hline $\begin{array}{l}\text { Presence of threat and } \\
\text { availability of suitable shelter }\end{array}$ & Hiding & $\begin{array}{l}\text { Avoiding threat or predator; } \\
\text { reduction of stress response; } \\
\text { increased likelihood of } \\
\text { obtaining prey }\end{array}$ \\
\hline
\end{tabular}

My explanation of these complex and impressive behaviors should not be misinterpreted as an argument that cognitive, internal processes or private events are not occurring within the octopus; rather, I argue that there are advantages to explaining behavior in the context of their antecedents and consequences. First, it provides a relatively straightforward way to identify the observable environmental events that influence behavior; this allows us to design environments that will promote these behaviors. Second, we can see that these are not merely stimulusresponse relations but rather voluntary behaviors that are products of learning about consequences in the animal's environment (Delprado \& Midgeley, 1992). This is already strong evidence that the octopus is sentient and worthy of good welfare standards. A third benefit of understanding behavior in this way is that it demonstrates that octopuses engage in learning that results in the avoidance of aversive events (e.g., hiding, "Passing Cloud," skin color changes) and that increases the likelihood of appetitive outcomes (e.g., copulation, consumption of prey, stress reduction) - further evidence that they are sentient. It can serve the animal to analyze whether these behaviors are the result of more basic behavioral processes with which we can explain how octopuses learn without inferring unnecessarily complex constructs. This can lead to a better understanding of octopus capabilities and hence to ways to arrange their environments to promote their welfare.

\section{Behavior-Analytic Approach to Enriching the Octopus "Mind"}

In animal husbandry, environmental enrichment is used to enhance physical and psychological wellbeing by promoting opportunities for species-typical behaviors, novel sensory stimulation, and more behavioral choice (Shepherdson, 1999). There are many studies on enrichment for charismatic mammalian and avian species, but effective enrichment for invertebrates is seldom systematically studied, as Mather notes (p. 15). 
Below are some examples of cephalopod enrichment strategies and behavioral goals for each, based on Mather's review. Considering behavior-driven enrichment in this way can help promote opportunities for octopuses to express species-typical behaviors and engage in complex learning in artificial environments:

\begin{tabular}{|l|l|l|}
\hline Behavioral System or Need & $\begin{array}{l}\text { Behavioral Goal (Established } \\
\text { Beforehand and Evaluated) }\end{array}$ & Enrichment Strategies \\
\hline Motor & $\begin{array}{l}\text { Locomotion of } \\
\text { body/appendages; moving } \\
\text { about different areas of } \\
\text { enclosure }\end{array}$ & $\begin{array}{l}\text { Provision of new } \\
\text { structures/décor or arranging } \\
\text { them in different ways } \\
\text { around environment }\end{array}$ \\
\hline Tactile & $\begin{array}{l}\text { Grasping with tentacles or } \\
\text { use of water "jetting" (may } \\
\text { include "solitary play") }\end{array}$ & $\begin{array}{l}\text { Provision of puzzles, Lego } \\
\text { blocks (Kuba, Byrne, Meisel, } \\
\text { \& Mather, 2006), floating pill } \\
\text { boxes (Mather \& Anderson, } \\
\text { 1999) or coconut shells } \\
\text { (observed in wild octopuses, } \\
\text { used to hide in) }\end{array}$ \\
\hline Visual & $\begin{array}{l}\text { Visual or ocular stimulation } \\
\text { or "Passing Cloud" }\end{array}$ & $\begin{array}{l}\text { Provision of mirror (Mather, } \\
\text { Carere, Fiorito, \& Anderson, } \\
\text { 2018) }\end{array}$ \\
\hline Foraging & $\begin{array}{l}\text { Food-seeking behavior and } \\
\text { successful consumption }\end{array}$ & $\begin{array}{l}\text { Provision of live prey in } \\
\text { puzzles or jars }\end{array}$ \\
\hline
\end{tabular}

This list is just a sample; an enrichment strategy could target multiple behavioral goals or go beyond this list. Reinforcement-based training could be enriching for captive animals; octopuses could be taught to collaborate in their care (e.g., station them in or target them to a specific area for feeding, train them to present body parts for routine medical checks or examination). Cognitive tests could serve as enrichment. Mather notes that octopuses "made more Mantle-Up challenge displays to conspecifics and more Passing Cloud displays to the mirror," although they did not pass the mirror self-recognition task (p. 6). Mirrors might serve as visual enrichment. The methods or stimuli to test for "tool use" or "self-awareness" might also be useful for welfare.

Mather notes that octopuses are flexible learners. They may habituate to frequently presented stimuli and instead try out different ways to obtain an outcome when a previously reinforced behavior is no longer effective. This is called extinction-induced variability (Neuringer, Kornell, \& Olafs, 2001); it might help in evaluating whether an enrichment or training strategy is effective or the reward is of sufficient value to keep responding. Many other applications from the experimental analysis of behavior are available (Tarou \& Bashaw, 2009) and would be wellsuited in creating welfare-positive environments for octopuses.

Good welfare must be a high priority for these intelligent invertebrates, as it is for vertebrates. If an animal's environment fails to provide opportunities for species-typical behaviors and for the complex forms of learning of which octopus are capable, then scientists, industry professionals, and society as whole must question whether using them is ethical or warranted. Mather's contribution provides us with a strong start in making informed judgments. 


\section{References}

Delprato, D. J., \& Midgley, B. D. (1992). Some fundamentals of BF Skinner's behaviorism. American Psychologist, 47(11), 1507.

Kuba, M. J., Byrne, R. A., Meisel, D. V., \& Mather, J. A. (2006). When do octopuses play? Effects of repeated testing, object type, age, and food deprivation on object play in Octopus vulgaris. Journal of Comparative Psychology, 120(3), 184.

Mather, J. (2019). What is in an octopus's mind? Animal Sentience 26(1).

Mather, J. A., \& Anderson, R. C. (1999). Exploration, play and habituation in octopuses (Octopus dofleini). Journal of Comparative Psychology, 113(3), 333.

Mather, J. A., Carere, C., Fiorito, G., \& Anderson, R. C. (2018). Octopuses and mirrors: A tale of two species. Paper presented at the annual meeting of the Animal Behavior Society, Milwaukee, WI.

Moxley, R. A. (1996). The import of Skinner's three-term contingency. Behavior and Philosophy, 24(2), 145-167.

Neuringer, A., Kornell, N., \& Olufs, M. (2001). Stability and variability in extinction. Journal of Experimental Psychology: Animal Behavior Processes, 27(1), 79.

Shepherdson, D. J., \& Mellen, J. D. (1999). Second nature: Environmental enrichment for captive animals. Smithsonian.

Tarou, L. R., \& Bashaw, M. J. (2007). Maximizing the effectiveness of environmental enrichment: Suggestions from the experimental analysis of behavior. Applied Animal Behaviour Science, 102(3-4), 189-204. 